\title{
AuguSTO ROA BASTOS E CÁNDIDO LÓPEZ: INVENÇÃO DE REALIDADES NA GUERRA GRANDE
}

Gislaine A. Michel

Mestre em Letras - Estudos Literários

\section{RESUMO}

Propõe-se neste ensaio, de maneira sucinta, verificar como a literatura articula-se com a história, a tradição, o mito, a memória e o imaginário nacional para a (re)construção de uma identidade paraguaia na obra do escritor paraguaio Augusto Roa Bastos.

\section{PALAVRAS-CHAVE}

Roa Bastos, Cándido López, Guerra Grande, literatura, ficção testemunhal

Escrever sobre Roa Bastos implica necessariamente evocar outros textos escritos. As análises de sua obra, sua biografia, as entrevistas concedidas constituem um vasto material disponível. Nesse universo de informações torna-se praticamente impossível tratar de sua produção sem abordar temas já explorados. Assim, sem aspirar ao status de originalidade, pretende-se estudar como a narrativa de Roa Bastos, pela articulação da literatura com a história, o mito, a tradição e a memória, consegue converter tais elementos em constituintes de outras realidades simbólicas, que não necessariamente refletem a realidade da qual foram extraídos.

A característica de escrever uma contra-história capaz de transgredir a história oficial é marca registrada de Roa Bastos, demonstrada pela vasta fortuna crítica de suas obras, em especial em relação aos romances Yo, El Supremo e Hijo de hombre. Entretanto, tal característica não significa uma eterna repetição do mesmo na obra do escritor. As reinterpretações dos conflitos culturais próprios do Paraguai assumem, em cada narrativa, novas significações. Embora partindo de características peculiares de seu país, tais como a forte herança da tradição oral guarani, a diglossia entre o espanhol e a língua indígena, o histórico de isolamento desde os tempos de colônia, o extermínio de quase uma geração como resultado da Guerra Grande e a sucessão de ditaduras no poder até o século 20, a escrita de 
Roa Bastos não se circunscreve às questões paraguaias. A utilização destes elementos não determina que a sua seja uma narrativa histórica. Os acontecimentos e/ou personagens históricos presentes em seus textos constituem-se como referentes ficcionais através dos quais o escritor propõe questões universais, tais como a relação entre história e ficção, entre memória e esquecimento, entre mito e tradição, entre o imaginário nacional e o poder.

Concebendo o texto como algo dinâmico, suscetível de ser corrigido pelo autor sem que isso acarrete a perda de sua natureza originária, Roa Bastos elegerá a poética das variações como guia de sua produção literária. Tal mecanismo constitui seu procedimento estético e seu compromisso ético com a escrita. Por sua vez, esta poética permite ao escritor transpor para a escrita as características da oralidade, reproduzindo dessa maneira os conflitos do duplo mundo linguístico paraguaio. A apropriação da oralidade nas sucessivas reescritas dos textos de Roa Bastos conduz a uma poética das variações que permite reinterpretar a história e o papel da linguagem nesta história.

Não se considerando um escritor profissional, Roa escreve para aclarar seus enigmas, os quais, por sua vez, estão inextricavelmente associados com os da coletividade paraguaia. E é na literatura que sua luta por justiça e liberdade se manifesta. Diante de uma história imposta pelos vencedores, considerada como bastarda, o escritor irá se valer de referências históricas para escrever uma contra-história, que opera pela ficção um questionamento dos fundamentos ideológicos da história oficial. Para compor as novas realidades através das variações, repetições, reinterpretações e versões de diversos textos, o autor cede lugar ao compilador. E as matérias-primas desse compilador são os refugos das versões consagradas da história. A poética das variações dá forma aos textos que compõem os palimpsestos que subvertem a ordem estabelecida e que o compilador, através dessa poética, arquiva e decifra como novas realidades.

A partir dos anos 1990, a Guerra Grande, conhecida no Brasil como Guerra do Paraguai (1864-1870), passa a ter maior relevância no universo narrativo de Roa Bastos. Novos personagens surgem tendo como base figuras históricas envolvidas nesse conflito do século 19. É no contexto dessa guerra que se situam os textos Em frente à frente argentina e Em frente à frente paraguaia, textos-chave deste estudo. Ambos constituem a participação de Roa Bastos, representando o Paraguai, na obra coletiva intitulada O livro da Guerra Grande (2002). Esse é o título que recebeu no Brasil a tradução da obra Los Conjurados del Quilombo del Gran Chaco. Nesse livro, quatro escritores de nacionalidades diferentes compõem seus textos tendo como ponto de partida uma comunidade de desertores da Guerra Grande. Essa comunidade, mencionada por Sir Richard Burton (1821-1890) em sua obra Cartas dos 
campos de batalha do Paraguai (2001), seria formada pelos desertores dos países envolvidos no grande conflito sul-americano do século 19, a saber: Paraguai, Argentina, Uruguai e Brasil. O projeto literário reúne, por sua vez, um representante de cada um dos países envolvidos na guerra, os quais abordam ficcionalmente fatos e personagens dos campos de batalha.

Destaca-se, nos textos de Roa Bastos, o personagem de Cándido López, recriado literariamente a partir da figura histórica do pintor argentino, voluntário da guerra e cujos quadros se converteram em registros oficiais da contenda. Procura-se demonstrar, pela análise desse personagem ficcional, como Roa Bastos revisa, reinterpreta e reelabora os fatos relacionados à Guerra Grande e como, a partir dessa desestruturação da história oficial, torna possível inventar novas realidades. Esse processo constitui a base de seu projeto narrativo, o qual procura denunciar a manipulação política da história pelo poder.

Em frente à frente argentina opõe em um diálogo as figuras de Bartolomé Mitre (1821-1906), Comandante-em-chefe das forças aliadas e presidente da República Argentina, e seu oficial tenente, o futuro pintor da guerra, Cándido López (1840-1902), estando ambos no campo de batalhas argentino. Historicamente, Cándido López se alistou como oficial e participou das batalhas até perder sua mão direita por estilhaços de granada na Batalha de Curupaytí. Afastado dos combates, treinou sua mão esquerda e em 1885 expôs uma série de quadros intitulada Escenas de la Guerra del Paraguay. Quanto a Bartolomé Mitre, além de estadista e general, iniciou a tradução do Inferno da Divina Comédia durante a própria guerra. O texto apresenta o diálogo de Mitre com Cándido López ao mesmo tempo que o primeiro traduz os versos dos círculos do inferno e o segundo faz esboços e pinta as batalhas das quais participou.

Ficcionalizando as vozes do passado por meio de Bartolomé Mitre e Cándido López, Em frente à frente argentina questiona os problemas da representação, apresenta novas interpretações do conflito, propõe reflexões sobre a leitura da história e dos valores relacionados à nação. Por um lado, temos em Mitre a grande figura representativa da nação argentina. Por sua vez, Cándido López pode ser lido como o refugo da história oficial, dado o esquecimento em que se viu mergulhado por anos. E é pelo personagem do pintor argentino que as leituras nacionalistas da guerra serão desmontadas. Tanto a pintura quanto a tradução, através dos meios específicos de cada uma, compartilham uma questão em comum: a representação. As pinturas de Cándido López, ao não seguirem a orientação nacionalista do comandante argentino, denunciam o discurso do poder. "É preciso inventar a glória, mestre. 
Se nossas tropas recuaram, faça com que avancem em sua pintura.” ${ }^{1}$ E os questionamentos de Cándido denunciam as limitações do trabalho de tradução de Mitre do Inferno, de Dante, por sua incapacidade de incorporar o universo linguístico e cultural americano à sua prática. "Não gosto do último verso, senhor. A frase é demasiado fina para o sentido demasiado grosso da idéia. Eu deixaria, com todo respeito a seu digno ofício, melhor, 'como víbora muda entre la hierba'."2 As sucessivas perguntas do pintor acabam também por desmontar as leituras nacionalistas do conflito. O discurso literário mostra que o argumento da luta contra a tirania paraguaia escondia as fracas bases formais das democracias dos países da Tríplice Aliança, as quais excluíam de sua participação os índios e os escravos.

Em frente à frente paraguaia divide-se em três partes. Na primeira delas, o capitão inglês Sir Richard Burton, mundialmente conhecido pela tradução das Mil e uma noites, tem um encontro fictício com Solano López e Madame Lynch próximo ao fim da guerra, nas tendas de campanha do Marechal. Homem de seu tempo, Burton foi explorador, cientista e naturalista, soldado, escritor e tradutor, diplomata e agente secreto. Em 1865 foi designado Cônsul em Santos, província de São Paulo. Viajou pelos países envolvidos na Guerra Grande e ao retornar à Inglaterra publicou em 1870 o livro Letters from the battlefields of Paraguay, traduzido no Brasil por Cartas dos campos de batalha do Paraguai. Nesse livro, após uma longa introdução, ele narra o desenrolar dos acontecimentos relacionados à guerra através de vinte e sete cartas endereçadas ao anônimo “Z...”. O livro foi dedicado a Don Domingo Faustino Sarmiento, presidente da República Argentina e conhecido por seu espírito modernizador, autor de Facundo. De narrador das Cartas, Richard Burton se converte em personagem que trava com Solano López também um diálogo sobre a guerra, agora sob a perspectiva das ações do dirigente paraguaio. As duas partes restantes abordam os temas da arte e da violência, através da introdução nos relatos do pintor paraguaio Cándido López, homônimo do oficial argentino. A figura desse duplo permitirá tanto os questionamentos dos valores veiculados pelo nacionalismo quanto os relativos à identidade intercultural dos países envolvidos no conflito.

Em frente à frente paraguaia já se inicia por um paradoxo. Bibliotecas inteiras foram escritas sobre a Guerra Grande e ela continua sendo desconhecida em seus aspectos mais relevantes. “A história oficial dos vencedores não fez senão obscurecê-la ainda mais e torná-la

\footnotetext{
${ }^{1}$ ROA BASTOS et al. O livro da Guerra Grande, p. 16.

${ }^{2}$ ROA BASTOS et al. O livro da Guerra Grande, p. 38. (grifo no original).
} 
inverossímil, como uma tragédia que não ocorreu nem poderia ter ocorrido.” Cabe também à literatura recuperar esse passado tornado inverossímil pelos resgates dos registros do passado. E aqui esse resgate opera-se por meio das cartas de Sir Richard Burton e pela presença do mito do Cándido López paraguaio. Sir Richard Burton, enquanto autor das Cartas dos campos de batalha do Paraguai, representa o discurso do dominador estrangeiro sobre as questões da América do Sul. Ao convertê-lo em personagem, Roa Bastos desmonta essa estrutura do europeu como único produtor e detentor de conhecimentos sobre questões ligadas ao nosso continente. E se o Cándido López argentino permaneceu entre os vencedores, pintando “o avance triunfal das tropas empenachadas de púrpura e gauda”, ${ }^{4}$ tornou-se necessária a criação do mito do Cándido López paraguaio para pintar a tragédia que a história oficial quis extinguir: “o massacre de um povo desarmado, nu e faminto”. ${ }^{5}$ O mito de Cándido está aí para contrastar com os dilemas culturais do Paraguai, funcionando como um outro polo das contradições, e mostra um lado esquecido da história desse país, ou seja, a tragédia da devastação da população masculina. Além disso, a resistência e persistência do personagem em continuar seu ofício de pintar as cenas da destruição com o pincel apertado entre os dentes, mesmo após a perda consecutiva de todos seus membros, fornecem uma imagem da construção da identidade nacional paraguaia.

Tradição, mito, história, memória, identidade nacional e ficção entrecruzam-se nesses textos de Roa Bastos permitindo a problematização do discurso historicista e proporcionando uma reflexão sobre alguns vetores da literatura contemporânea, na condição de mecanismos de resistência aos poderes institucionalizados, dentro do discurso da pós-modernidade.

\footnotetext{
${ }^{3}$ ROA BASTOS et al. O livro da Guerra Grande, p. 55.

${ }^{4}$ ROA BASTOS et al. O livro da Guerra Grande, p. 96.

${ }^{5}$ ROA BASTOS et al. O livro da Guerra Grande, p. 96.
} 


\section{RESUMEN}

Se propone en este ensayo, de manera sucinta, verificar como la literatura se articula con la historia, la tradición, el mito, la memoria y el imaginario nacional para la (re)construcción de una identidad paraguaya en la obra del escritor paraguayo Augusto Roa Bastos.

\section{PALABRAS-CLAVE}

Roa Bastos, Cándido López, Guerra Grande, literatura, ficción testimonial

\section{REFERÊNCIAS}

ANDERSON, Benedict. Comunidades Imaginadas: reflexões sobre a origem e a expansão do Nacionalismo. Trad. Catarina Mira. Lisboa: Edições 70, 2005.

BRANDÃO, Luis Alberto. Grafias da identidade: literatura contemporânea e imaginário nacional. Rio de Janeiro: Lamparina Editora; Belo Horizonte: FALE-UFMG, 2005.

BURTON, Richard Francis. Cartas dos Campos de batalha do Paraguai. Trad. e notas de José Lívio Dantas. 2. reimpr. Rio de Janeiro: Biblioteca do Exército, 2001.

CÁRCAMO, Silvia Inés. Nación, tragedia Y mesianismo (El último ciclo narrativo de Augusto Roa Bastos). 2007. Disponível em: <http://www.letras.ufmg.br/ espanhol/NACI\%C3\%93N,\%20TRAGEDIA\%20Y\%20MESIANISMO.htm>. Acesso em: 29 maio 2007.

CÁRCAMO, Silvia Inés. Família, nación y poética en Roa Bastos. Rio de Janeiro, 2008. Inédito.

CASTORIADIS, Cornelius. A criação histórica e a instituição da sociedade. In: . et al. A criação histórica. Trad. Dênis L. Rosenfield. Porto Alegre: Artes e Ofícios Editora Ltda., 1992. p. 83-101.

CUADERNOS HISPANOAMERICANOS: homenaje a Roa Bastos. Madrid, n. 493/494, jul.ago. 1991.

DINIZ, Alai Garcia. Máquinas, corpos, cartas: imaginários da Guerra do Paraguai. 1997. Tese (doutorado em Letras) - Faculdade de Filosofia, Letras e Ciências Humanas, Universidade de São Paulo, São Paulo, 1997.

DORATIOTO, Francisco. Maldita guerra: nova história da Guerra do Paraguai. São Paulo: Cia. das Letras, 2002.

GUERRERO, Jorge Carlos. Augusto Roa Bastos y Los Conjurados del Quilombo del Gran Chaco (2001): un legado literario para la integración latinoamericana. Revista Iberoamericana, v. LXXIII, n. 218-219, p. 237-251, enero-junio 2007.

IPARRAGUIRRE, Sylvia. Cándido López. In: Pintura argentina: panorama del período 1810-2000. Volumen dedicado a Cándido López. Buenos Aires: Departamento de promoción cultural del grupo Velox, n. 3, mayo 2001.

LOUVEL, Liliane. A descrição "pictural”: por uma poética do iconotexto. In: ARBEX, 
Márcia (Org.). Poéticas do visível: ensaios sobre a escrita e a imagem. Belo Horizonte: PósLit/ FALE-UFMG, 2006. p. 191-220.

PACHECO, Glória Elizabeth Saldivar de. Augusto Roa Bastos: o fazer literário como interpelação da história paraguaia. 2006. Dissertação (Mestrado em Literatura Comparada) Instituto de Letras, Universidade Federal do Rio Grande do Sul, Porto Alegre, 2006.

PEREIRA, Flávio. A poetização da Guerra do Paraguai em "Los conjurados del Quilombo del Gran Chaco”. 2006. Dissertação (Mestrado em Letras) - Universidade Estadual Paulista Júlio de Mesquita Filho, UNESP, São Paulo, 2006.

PINTURA argentina: panorama del período 1810-2000. Volumen dedicado a Cándido López. Buenos Aires: Departamento de Promoción Cultural del Grupo Velox, n. 3, mayo 2001.

REVISTA ÁNTHROPOS. Augusto Roa Bastos: la escritura, memoria del agua, la voz y la sangre - una poética de las variaciones. Barcelona: Editorial del hombre, n. 115, dic. 1990.

RICEUR, Paul. La memoria ejercida: uso y abuso. In: La memoria, la historia, el olvido. Trad. Agustín Neira. Buenos Aires: Fondo de Cultura Económica de Argentina, 2000. p. 96-123.

ROA BASTOS, Augusto. El ojo de la luna. Cuadernos Hispanoamericanos: homenaje a Roa Bastos. Madrid, n. 493/494, p. 13-23, jul./ago. 1991a.

ROA BASTOS et al. O livro da Guerra Grande. Trad. Josely Vianna Baptista et al. Rio de Janeiro: Record, 2002.

ROCHA, João Cezar de Castro. Teoria da ficção: indagações à obra de Wolfang Iser. João Cezar de Castro Rocha (Org.). Trad. Bluma Waddington Vilar. Rio de Janeiro: EdUERJ, 1999. 